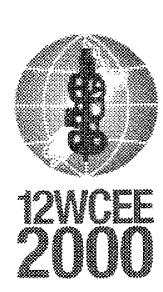

\title{
ACTIVE, SEMI-ACTIVE AND HYBRID CONTROL OF STRUCTURES
}

\author{
T T SOONG ${ }^{1}$ And B F SPENCER, $\mathrm{JR}^{2}$
}

\begin{abstract}
SUMMARY
In recent years, considerable attention has been paid to research and development of passive and active structural control devices, with particular emphasis on alleviation of wind and seismic response of buildings and bridges. In both areas, serious efforts have been undertaken to develop the structural control concept into a workable technology, and today we have many such devices installed in a wide variety of structures.

The focus of this state-of-the-art paper is on active, semi-active and hybrid structural control with seismic applications. These systems employ controllable force devices integrated with sensors, controllers and real-time information processing. This paper includes a brief historical outline of their development and an assessment of the state-of-the-art and state-of-the-practice of this exciting, and still evolving, technology. Also included in the discussion are their advantages and limitations in the context of seismic design and retrofit of civil engineering structures.
\end{abstract}

\section{INTRODUCTION}

Active, semi-active and hybrid structural control systems are a natural evolution of passive control technologies such as base isolation and passive energy dissipation. The possible use of active control systems and some combinations of passive and active systems, so called hybrid systems, as a means of structural protection against wind and seismic loads has received considerable attention in recent years. Active/hybrid control systems are force delivery devices integrated with real-time processing evaluators/controllers and sensors within the structure. They act simultaneously with the hazardous excitation to provide enhanced structural behavior for improved service and safety. Remarkable progress has been made over the last twenty years. The First and Second World Conferences on Structural Control held in 1994 [Housner et al, 1994b] and 1998 [Kobori et al, 1998], respectively, attracted over 700 participants from 17 countries and demonstrated the worldwide interest in structural control. As will be discussed in the following sections, research to date has reached the stage where active systems have been installed in full-scale structures. Active systems have also been used temporarily in construction of bridges or large span structures (e.g., lifelines, roofs) where no other means can provide adequate protection.

This rapid growth of research interest and development of active/hybrid structural control systems is in part due to several coordinated research efforts, largely in Japan and US, marked by a series of milestones listed in Table

1. Indeed, the most challenging aspect of active control research in civil engineering is the fact that it is an integration of a number of diverse disciplines, some of which are not within the domain of traditional civil engineering. These include computer science, data processing, control theory, material science, sensing technology, as well as stochastic processes, structural dynamics, and wind and earthquake engineering. These coordinated efforts have facilitated collaborative research efforts among researchers from diverse background and accelerated the research-to-implementation process as one sees today. 
Table 1: Active Structural Control Research - Milestones

\begin{tabular}{c|l}
\hline Year & \multicolumn{1}{|c}{ Event } \\
\hline 1989 & $\begin{array}{l}\text { US Panel on Structural Control Research } \\
\text { (US-NSF) } \\
\text { Japan Panel on Structural Response Control } \\
\text { (Japan-SCJ) } \\
\text { Five-year Research Initiative on Structural Control } \\
\text { (US-NSF) } \\
1990\end{array}$ \\
1993 & $\begin{array}{l}\text { European Association for Control of Structures } \\
\text { International Association for Structural Control }\end{array}$ \\
1994 & $\begin{array}{l}\text { First World Conference on Structural Control } \\
\text { (Pasadena, CA, USA) } \\
\text { China Panel for Structural Control } \\
1998\end{array}$ \\
\hline
\end{tabular}

The purpose of this paper is to provide an assessment of the state-of-the-art and state-of-the-practice of this exciting, and still evolving, technology. Also included in the discussion are some basic concepts, the types of active control systems being used and deployed, and their advantages and limitations in the context of seismic design and retrofit of civil engineering structures.

\section{ACTIVE, HYBRID AND SEMI-ACTIVE CONTROL SYSTEMS}

An active structural control system has the basic configuration as shown schematically in Fig. 1c. It consists of (a) sensors located about the structure to measure either external excitations, or structural response variables, or both; (b) devices to process the measured information and to compute necessary control force needed based on a given control algorithm; and (c) actuators, usually powered by external sources, to produce the required forces.

When only the structural response variables are measured, the control configuration is referred to as feedback control since the structural response is continually monitored and this information is used to make continual corrections to the applied control forces. A feedforward control results when the control forces are regulated only by the measured excitation, which can be achieved, for earthquake inputs, by measuring accelerations at the structural base. In the case where the information on both the response quantities and excitation are utilized for control design, the term feedback-feedforward control is used [Suhardjo et al, 1990].

To see the effect of applying such control forces to a linear structure under ideal conditions, consider a building structure modeled by an $n$-degree-of-freedom lumped mass-spring-dashpot system. The matrix equation of motion of the structural system can be written as

$$
M \ddot{x}(t)+C \dot{x}(t)+K \boldsymbol{x}(t)=\boldsymbol{D u}(t)+\boldsymbol{E} f(t)
$$

where $M, C$ and $K$ are the $n \times n$ mass, damping and stiffness matrices, respectively, $\boldsymbol{x}(t)$ is the $n$-dimensional displacement vector, the $m$-vector $f(t)$ represents the applied load or external excitation, and $r$-vector $\boldsymbol{u}(t)$ is the 


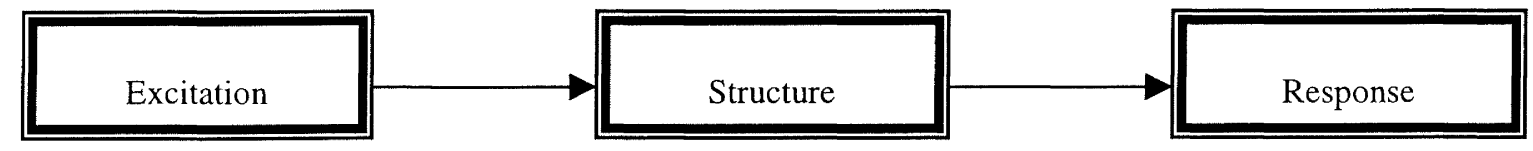

Figure 1a: Conventional Base Structure

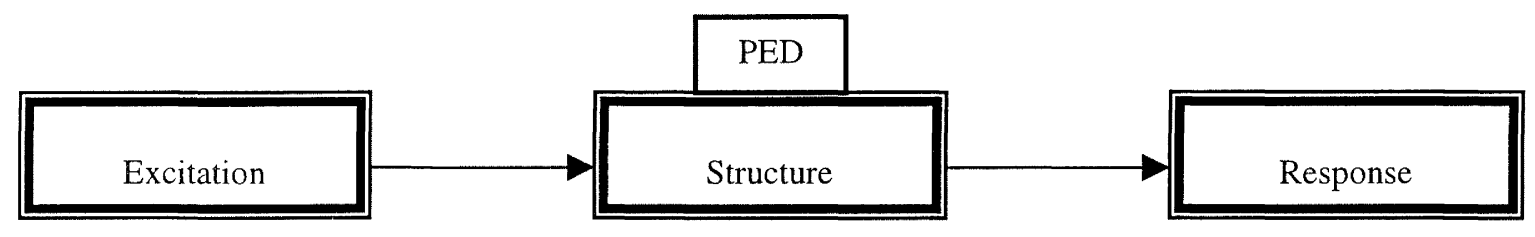

Figure 1b: Structure with Passive Energy Dissipation

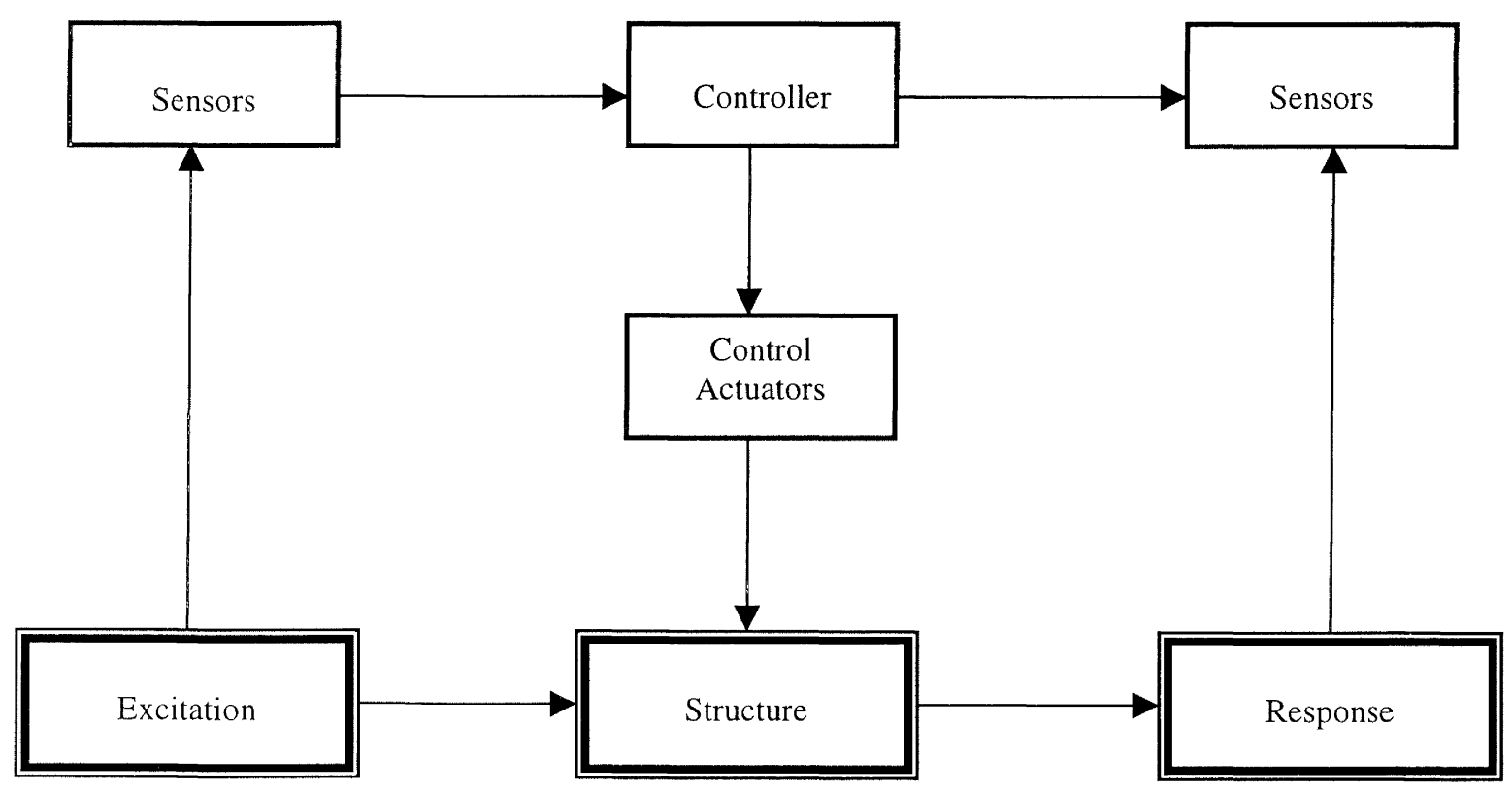

Figure 1c: Structure with Active Control

Figure 1: Structure with Various Control Schemes 


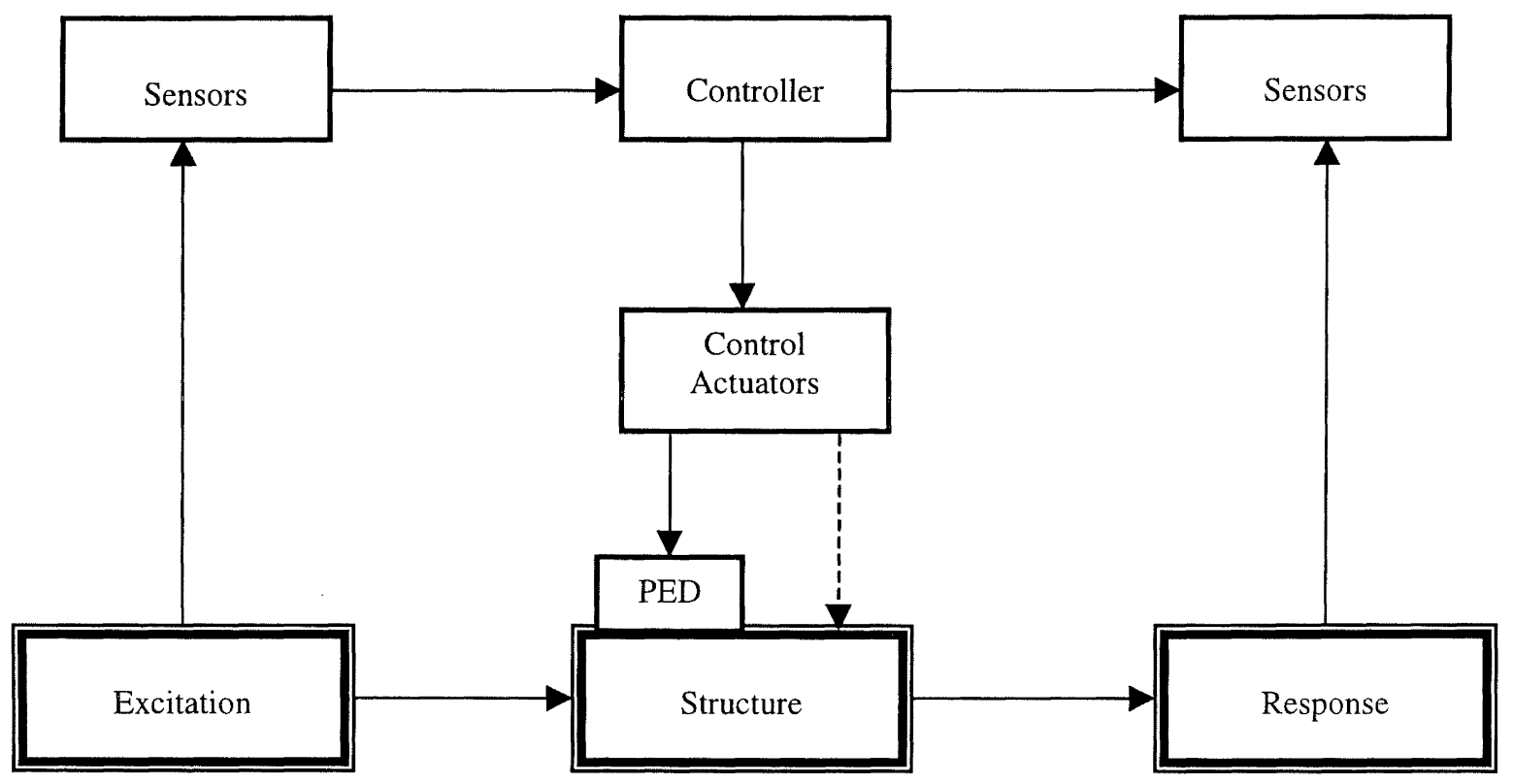

Figure 1d: Structure with Hybrid Control

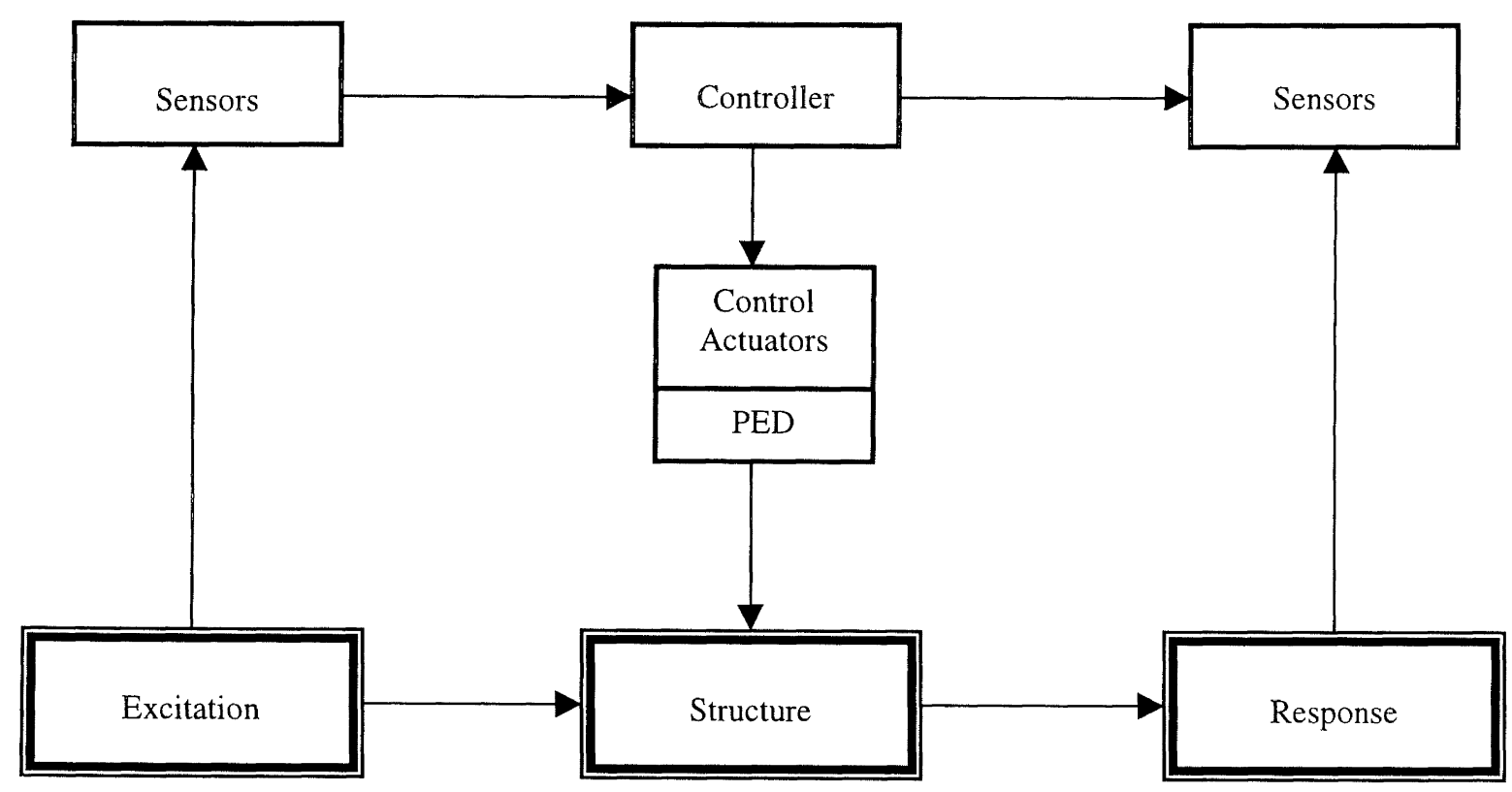

Figure 1e: Structure with Semi-active Control

Figure 1 (cont.): Structure with Various Control Schemes 
applied control force vector. The $n \times r$ matrix $\mathbf{D}$ and the $n \times m$ matrix $\mathbf{E}$ define the locations of the action of the control force vector and the excitation, respectively, on the structure.

Suppose that the feedback-feedforward configuration is used in which the control force $\boldsymbol{u}(t)$ is designed to be a linear function of measured displacement vector $\boldsymbol{x}(t)$, velocity vector $\dot{\boldsymbol{x}}(t)$ and excitation $\boldsymbol{f}(t)$. The control force vector takes the form

$$
\boldsymbol{u}(t)=\boldsymbol{G}_{x} \boldsymbol{x}(t)+\boldsymbol{G}_{\dot{x}} \dot{x}(t)+\boldsymbol{G}_{f} f(t)
$$

in which $\boldsymbol{G}_{x}, \boldsymbol{G}_{\dot{x}}$ and $\boldsymbol{G}_{f}$ are respective control gains which can be time-dependent.

The substitution of Eq. (2) into Eq. (1) yields

$$
\boldsymbol{M} \ddot{\boldsymbol{x}}(t)+\left(C-D G_{\dot{x}}\right) \dot{\boldsymbol{x}}(t)+\left(\boldsymbol{K}-\boldsymbol{D} \boldsymbol{G}_{\boldsymbol{x}}\right) \boldsymbol{x}(t)=\left(\boldsymbol{E}+\boldsymbol{D} \boldsymbol{G}_{f}\right) \boldsymbol{f}(t)
$$

Comparing Eq. (3) with Eq. (1) in the absence of control, it is seen that the effect of feedback control is to modify the structural parameters (stiffness and damping) so that it can respond more favorably to the external excitation. The effect of the feedforward component is a modification of the excitation. The choice of the control gain matrices $\boldsymbol{G}_{\boldsymbol{x}}, \boldsymbol{G}_{\dot{x}}$ and $\boldsymbol{G}_{f}$ depends on the control algorithm selected.

In comparison with passive control systems, a number of advantages associated with active control systems can be cited; among them are (a) enhanced effectiveness in response control; the degree of effectiveness is, by and large, only limited by the capacity of the control systems; (b) relative insensitivity to site conditions and ground motion; (c) applicability to multi-hazard mitigation situations; an active system can be used, for example, for motion control against both strong wind and earthquakes; and (d) selectivity of control objectives; one may emphasize, for example, human comfort over other aspects of structural motion during noncritical times, whereas increased structural safety may be the objective during severe dynamic loading.

While this description is conceptually in the domain of familiar optimal control theory used in electrical engineering, mechanical engineering, and aerospace engineering, structural control for civil engineering applications has a number of distinctive features, largely due to implementation issues, that set it apart from the general field of feedback control. In particular, when addressing civil engineering structures, there is considerable uncertainty, including nonlinearity, associated with both physical properties and disturbances such as earthquakes and wind, the scale of the forces involved can be quite large, there are only a limited number of sensors and actuators, the dynamics of the actuators can be quite complex, the actuators are typically very large, and the systems must be fail-safe [Soong, 1990; Housner et al, 1994a, 1997; Kobori, 1994; Dyke et al, 1995].

It is useful to distinguish among several types of active control systems currently being used in practice. The term hybrid control generally refers to a combined passive and active control system as depicted in Fig. 1d. Since a portion of the control objective is accomplished by the passive system, less active control effort, implying less power resource, is required.

Similar control resource savings can be achieved using the semi-active control scheme sketched in Fig. 1e, where the control actuators do not add mechanical energy directly to the structure, hence bounded-input bounded-output stability is guaranteed. Semi-active control devices are often viewed as controllable passive devices.

A side benefit of hybrid and semi-active control systems is that, in the case of a power failure, the passive components of the control still offer some degree of protection, unlike a fully active control system.

\section{FULL-SCALE APPLICATIONS}

As alluded to earlier, the development of active, hybrid, and semi-active control systems has reached the stage of full-scale applications to actual structures. Table 2 lists these installations in building structures and towers, most of which are in Japan. In addition, 15 bridge towers have employed active systems during erection [Fujino, 1994; Spencer and Sain, 1997]. Most of these full scale systems have been subjected to actual wind 
Table 2: Full Scale Implementation of Active Structural Control

\begin{tabular}{|c|c|c|c|c|c|}
\hline Location & Building & $\begin{array}{c}\text { Year } \\
\text { Completed }\end{array}$ & Buiding Use & $\begin{array}{l}\text { Number } \\
\text { of } \\
\text { Stories }\end{array}$ & $\begin{array}{c}\text { Type of } \\
\text { Vibration } \\
\text { Control } \\
\text { Device* }\end{array}$ \\
\hline \multirow[t]{37}{*}{ Japan } & Kyobashi Seiwa Bldg, Tokyo & 1989 & Office & 11 & AMD \\
\hline & Kajima Research Lab. \# 21, Tokyo & 1990 & Office & 3 & SAVS \\
\hline & Shimizu Tech. Lab., Tokyo & 1991 & Laboratory & 7 & AMD \\
\hline & Sendagaya INTES Bldg., Tokyo & 1992 & Office & 11 & HMD \\
\hline & Elevator Tech. Lab. & 1992 & Laboratory & $(60 \mathrm{~m})$ & AGS \\
\hline & Hankyu Chayamachi Bldg., Osaka & 1992 & Office/Hotel & 34 & HMD \\
\hline & Kansai Int'l Airport, Osaka & 1992 & Control Tower & $(88 \mathrm{~m})$ & HMD \\
\hline & Land Mark Tower, Yokohama & 1993 & Office/Hotel & 70 & HMD \\
\hline & Osaka Resort City 200, Osaka & 1993 & Office/Hotel & 50 & HMD \\
\hline & Long Term Credit Bank, Tokyo & 1993 & Office & 21 & HMD \\
\hline & Ando Nishikicho Bldg., Tokyo & 1993 & Office & 14 & HMD \\
\hline & $\begin{array}{l}\text { NTT Kuredo Motomach } \\
\text { Bldg., Hiroshima }\end{array}$ & 1993 & Office/Hotel & 35 & HMD \\
\hline & Penta-Ocean Exp. Bldg., Tokyo & 1994 & Experimental & 6 & HMD \\
\hline & Shinjuku Park Tower, Tokyo & 1994 & Office/Hotel & 52 & HMD \\
\hline & Dowa Fire \& Marine Ins., Osaka & 1994 & Office & 29 & HMD \\
\hline & Porte Kanazawa, Kanazawa & 1994 & Office/Hotel & 30 & AMD \\
\hline & Mitsubishi Heavy Ind., Yokohama & 1994 & Office & 34 & HMD \\
\hline & $\begin{array}{l}\text { Hamamatsu ACT Tower, } \\
\text { Hamamatsu }\end{array}$ & 1994 & Office/Hotel & $(212 \mathrm{~m})$ & HMD \\
\hline & Riverside Sumida, Tokyo & 1994 & Office & 33 & AMD \\
\hline & Hotel Ocean 45, Miyazaki & 1994 & Hotel & 43 & HMD \\
\hline & RIHGA Royal Hotel, Hiroshima & 1994 & Hotel & 35 & HMD \\
\hline & Hikarigaoko J City Bldg., Tokyo & 1994 & Office/Hotel & 46 & HMD \\
\hline & Osaka WTC Bldg., Osaka & 1995 & Office & 52 & HMD \\
\hline & $\begin{array}{l}\text { Dowa Kasai Phoenix Tower, } \\
\text { Osaka }\end{array}$ & 1995 & Office & 28 & HMD \\
\hline & Rinku Gate Tower Bldg., Osaka & 1995 & Office/Hotel & 56 & HMD \\
\hline & Hirobe Miyake Bldg., Tokyo & 1995 & Office/Residential & 9 & HMD \\
\hline & Plaza Ichihara, Chiba & 1995 & Office & 12 & HMD \\
\hline & Herbis Osaka, Osaka & 1997 & Hotel & 38 & AMD \\
\hline & $\begin{array}{l}\text { Nisseki Yokohama Bldg., } \\
\text { Yokohama }\end{array}$ & 1997 & Office & 30 & HMD \\
\hline & Itoyama Tower, Tokyo & 1997 & Office/Residential & 18 & HMD \\
\hline & Otis Shibyama Test Tower, Chiba & 1998 & Laboratory & 39 & HMD \\
\hline & Bunka Gakuen, Tokyo & 1998 & School & 20 & HMD \\
\hline & Daiichi Hotel Oasis Tower, Ohita & 1998 & Office/Hotel & 21 & HMD \\
\hline & Odakyu Southern Tower, Tokyo & 1998 & Office/Hotel & 36 & HMD \\
\hline & Kajima Shizuoka Bldg., Shizuoka & 1998 & Office & 5 & SAHD \\
\hline & $\begin{array}{l}\text { Sotetsu Takashimaya Kyoto Bldg., } \\
\text { Yokohama }\end{array}$ & 1998 & Hotel & 27 & HMD \\
\hline & Century Park Tower, Tokyo & 1999 & Residential & 54 & HMD \\
\hline USA & Highway I-35 Bridge, OK & 1997 & Highway Traffic & -- & SAHD \\
\hline Taiwan & TC Tower, Kaoshiung & 1999 & Office & 85 & HMD \\
\hline & Shin-Jei Bldg., Taipei & 1999 & Office/Commerce & 22 & HMD \\
\hline China & $\begin{array}{l}\text { Nanjing Communication } \\
\text { Tower, Nanjing }\end{array}$ & 1999 & Communication & $(310 \mathrm{~m})$ & AMD \\
\hline
\end{tabular}

*AMD: Active mass Dampers; SAVS: Semi-active variable stiffness; HMD: Hybrid mass damper;

SAHD: Semi-active hydraulic damper 
forces and ground motions and their observed performances provide invaluable information in terms of (a) validating analytical and simulation procedures used to predict actual system performance, (b) verifying complex electronic-digital-servohydraulic systems under actual loading conditions, and (c) verifying capability of these systems to operate or shutdown under prescribed conditions.

Described below are several of these systems together, in some cases, with their observed performances. Also addressed are several practical issues in connection with actual structural applications of these systems.

\section{Hybrid Mass Damper Systems}

As seen from Table 2, the hybrid mass damper (HMD) is the most common control device employed in fullscale civil engineering applications. An HMD is a combination of a passive tuned mass damper (TMD) and an active control actuator. The ability of this device to reduce structural responses relies mainly on the natural motion of the TMD. The forces from the control actuator are employed to increase the efficiency of the HMD and to increase its robustness to changes in the dynamic characteristics of the structure. The energy and forces required to operate a typical HMD are far less than those associated with a fully active mass damper system of comparable performance.

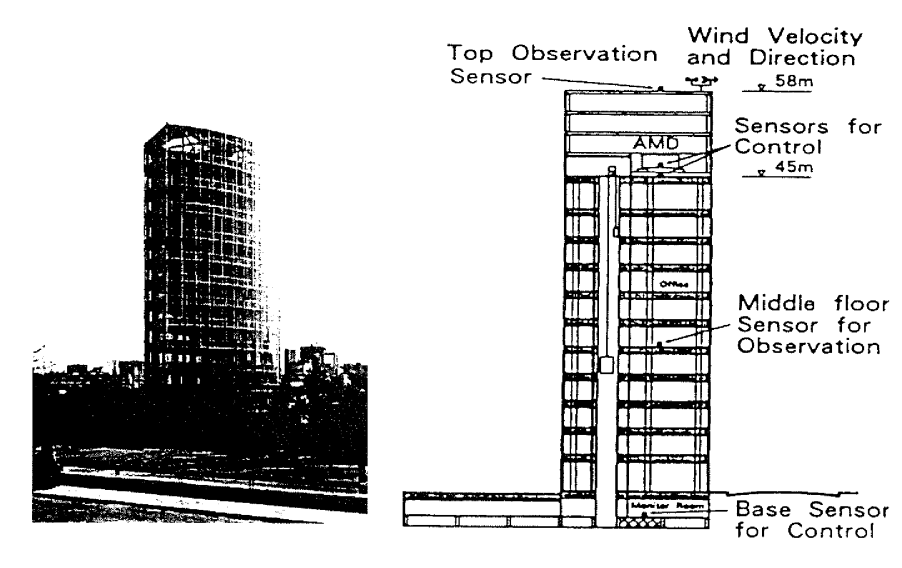

Figure 2: Sendagaya INTES Building

An example of such an application is the HMD system installed in the Sendagaya INTES building in Tokyo in 1991. As shown in Fig. 2, the HMD was installed atop the 11th floor and consists of two masses to control transverse and torsional motions of the structure, while hydraulic actuators provide the active control capabilities. The top view of the control system is shown in Fig. 3 where ice thermal storage tanks are used as mass blocks so that no extra mass must be introduced. The masses are supported by multi-stage rubber bearings intended for reducing the control energy consumed in the HMD and for insuring smooth mass movements [Higashino and Aizawa, 1993; Soong et al, 1994].

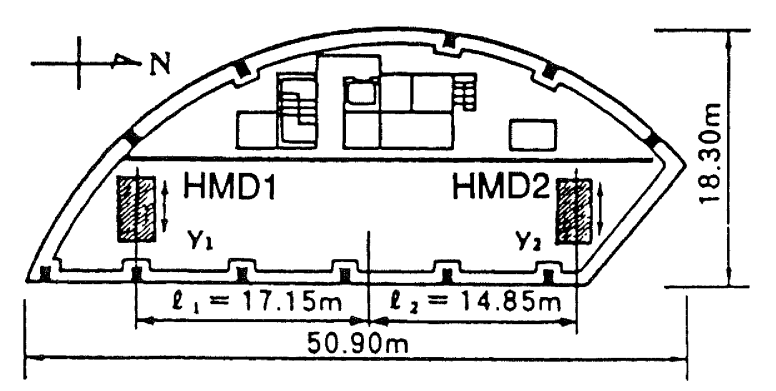

Figure 3: Top View of HMD

Sufficient data were obtained for evaluation of the HMD performance when the building was subjected to strong wind on March 29, 1993, with peak instantaneous wind speed of $30.6 \mathrm{~m} / \mathrm{sec}$. An example of the recorded time histories is shown in Fig. 4, giving both the uncontrolled and controlled states. Their Fourier spectra using samples of 30-second durations are shown in Fig. 5, again showing good performance in the low frequency range. The response at the fundamental mode was reduced by $18 \%$ and $28 \%$ for translation and torsion, 
respectively. Similar performance characteristics were observed during a series of earthquakes recorded between May, 1992 and February, 1993.

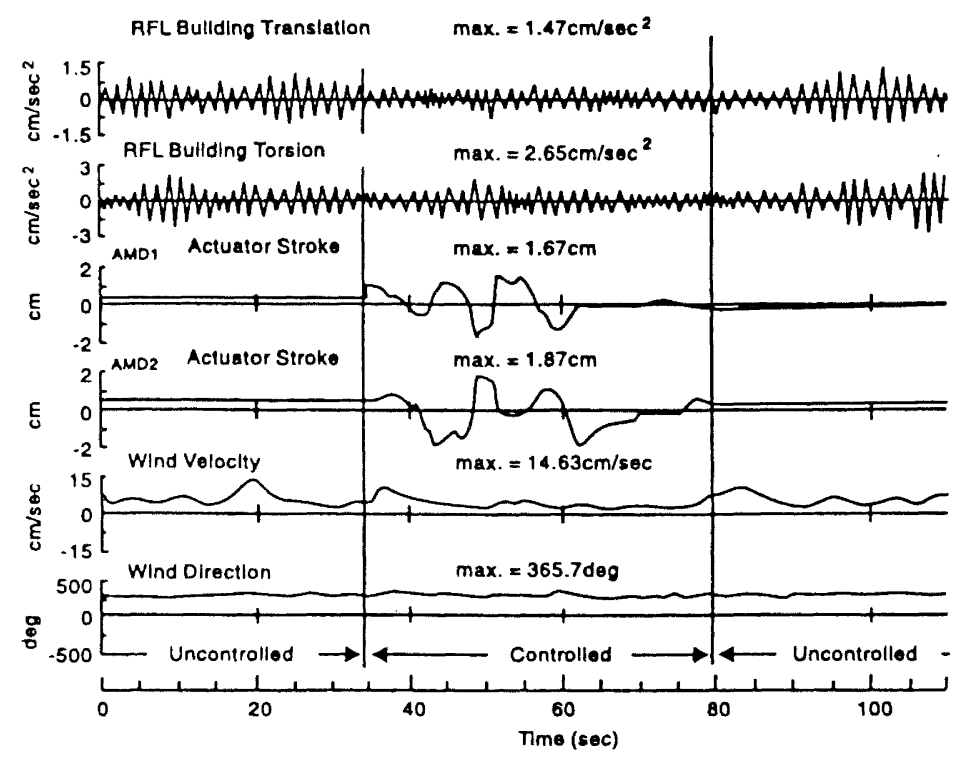

Figure 4: Response Time Histories (March 23, 1993)
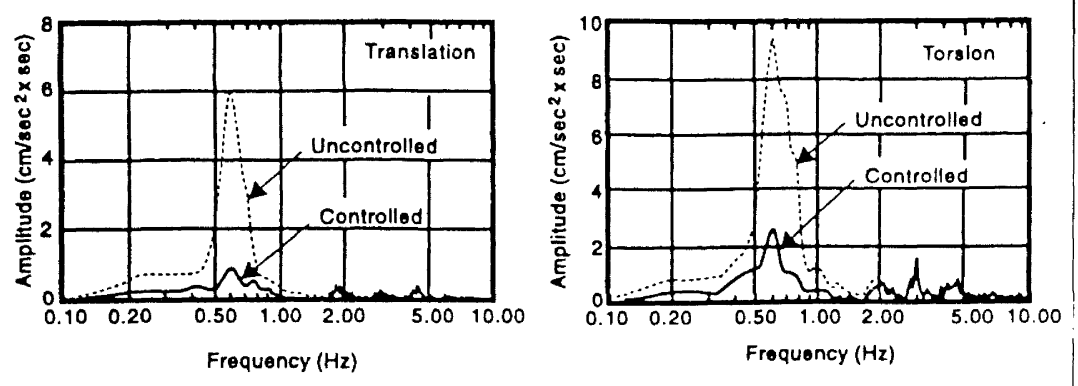

Figure 5: Response Fourier Spectra (March 23, 1993)

Variations of such an HMD configuration include multi-step pendulum HMDs (as seen in Fig. 6), which have been installed in, for example, the Yokohama Landmark Tower in Yokohama [Yamazaki et al, 1992], the tallest building in Japan, and in the TC Tower in Kaohsiung, Taiwan. Additionally, the DUOX HMD system which, as shown schematically in Fig. 7, consists of a TMD actively controlled by an auxiliary mass, has been installed in, for example, the Ando Nishikicho Building in Tokyo.
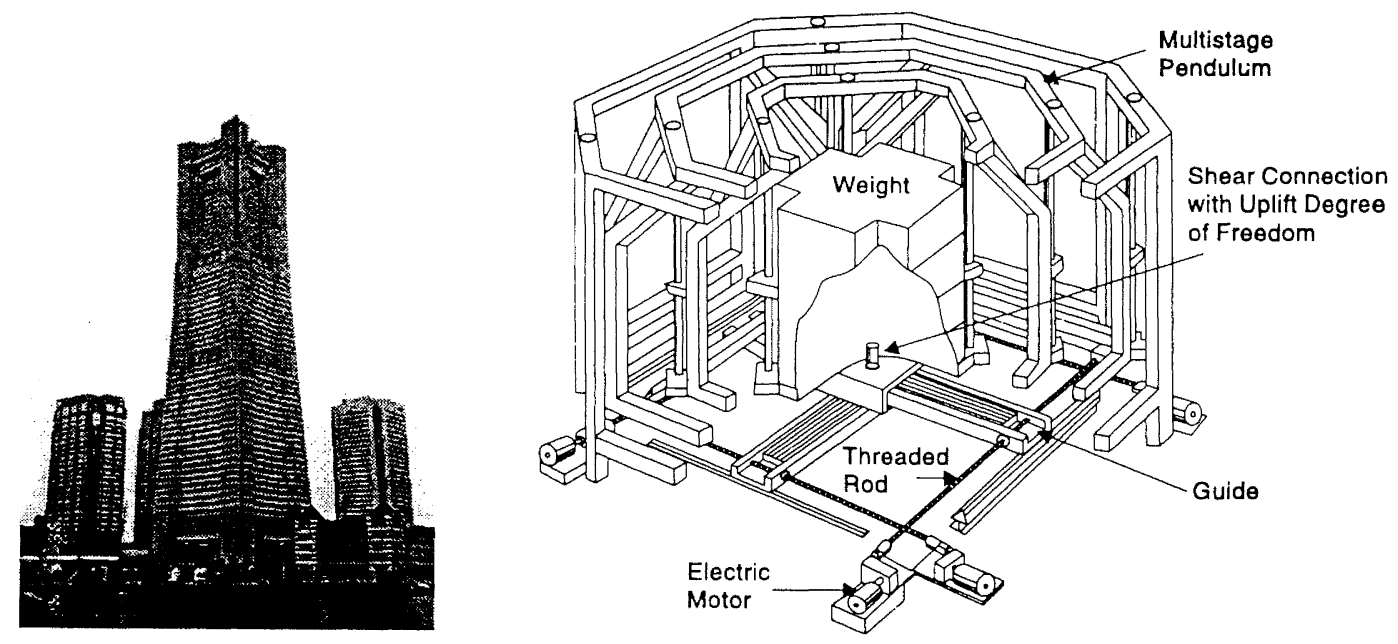

Figure 6: Yokohama Landmark Tower and HMD 


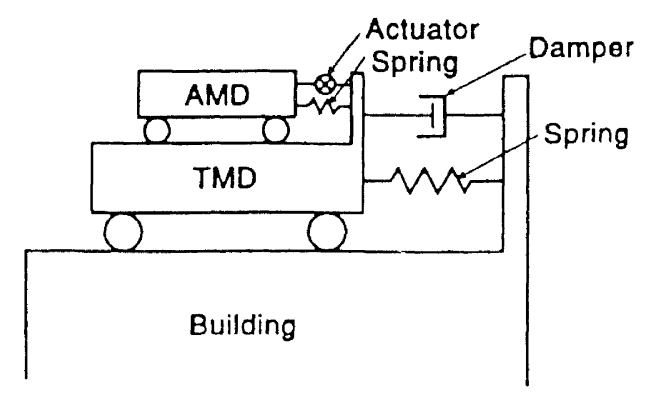

Fig. 7: Principle of DUOX System

\section{Active Mass Damper Systems}

Design constraints, such as severe space limitations, can preclude the use of an HMD system. Such is the case in the active mass damper or active mass driver (AMD) system designed and installed in the Kyobashi Seiwa Building in Tokyo and the Nanjing Communication Tower in Nanjing, China.

The Kyobashi Seiwa Building, the first full-scale implementation of active control technology, is an 11-story building with a total floor area of $423 \mathrm{~m}^{2}$. As seen in Fig. 8, the control system consists of two AMDs where the primary AMD is used for transverse motion and has a weight of 4 tons, while the secondary AMD has a weight of 1 ton and is employed to reduce torsional motion. The role of the active system is to reduce building vibration under strong winds and moderate earthquake excitations and consequently to increase comfort of occupants in the building.
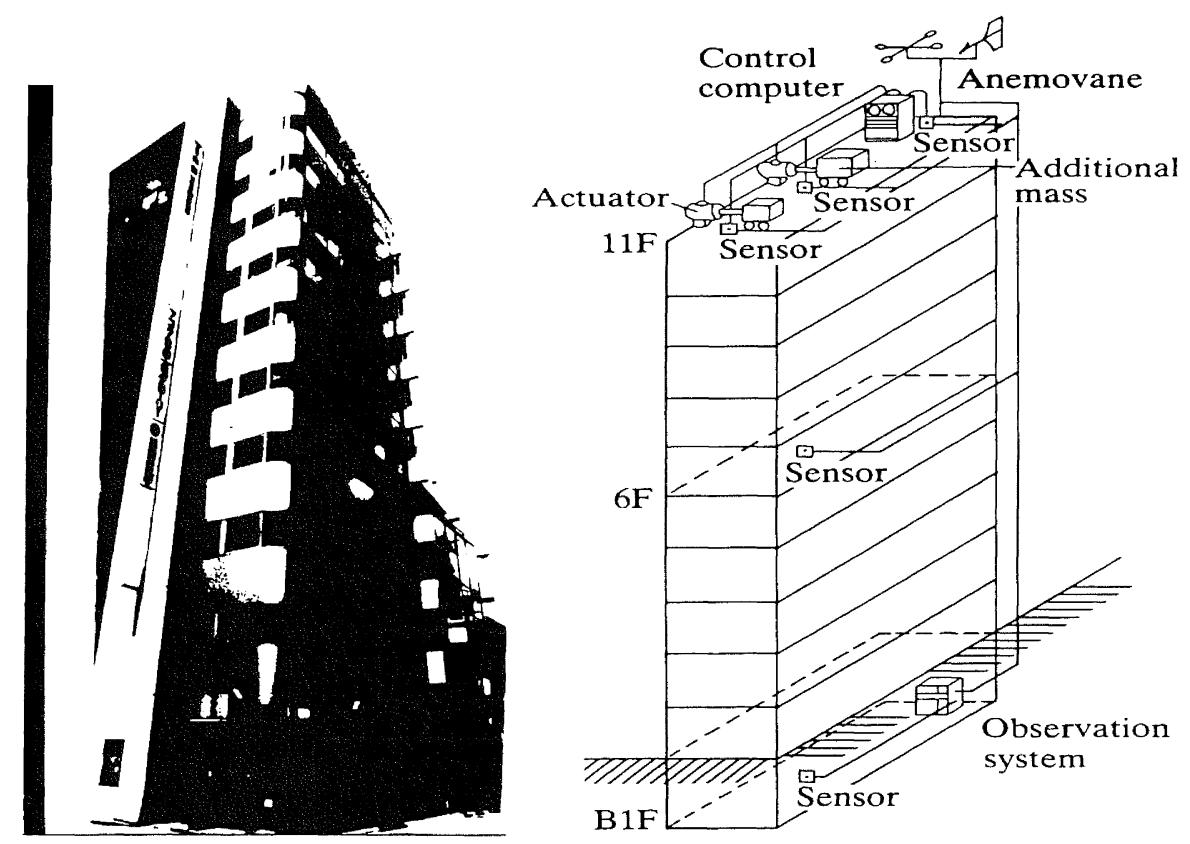

Figure 8: Kyobashi Seiwa Building and AMD

In the case of the Nanjing Communication tower (Fig. 9), numerous physical constraints had to be accounted for in the system design of the mass damper. The physical size of the damper was constrained to a ring-shaped floor area with inner and outer radii of $3 \mathrm{~m}$ and $6.1 \mathrm{~m}$, respectively. In addition, the damper was by necessity elevated off the floor on steel supports with Teflon bearings to allow free access to the floor area. The final ring design allowed the damper to move $\pm 750 \mathrm{~mm}$ from its rest position. Simulations indicate that this stroke is sufficient to control the tower; however, a greater stroke would allow substantially more improvement in the response. The strength of the observation deck limited the weight of the damper to 60 tons. Lack of sufficient lateral space made the use of mechanical springs impractical for restoring forces. Thus the active control actuators provide restoring force as well as the damping control forces. 
The final design of the active mass damper is shown in Fig. 10, which uses three servo-controlled hydraulic actuators, each with a total stroke of $\pm 1.50 \mathrm{~m}$ and a peak control force of $50 \mathrm{kN}$. These actuators are arranged $120^{\circ}$ apart around the circumference of the ring. The actuators control three degrees of freedom: two orthogonal lateral directions of motion and torsional rotation, which is held to zero. Since the frictional force between the Teflon bearings and mass can have a critical influence on the response of the system, a detailed analysis was performed to verify the system performance in the presence of this friction [Reinhorn et al, 1998].

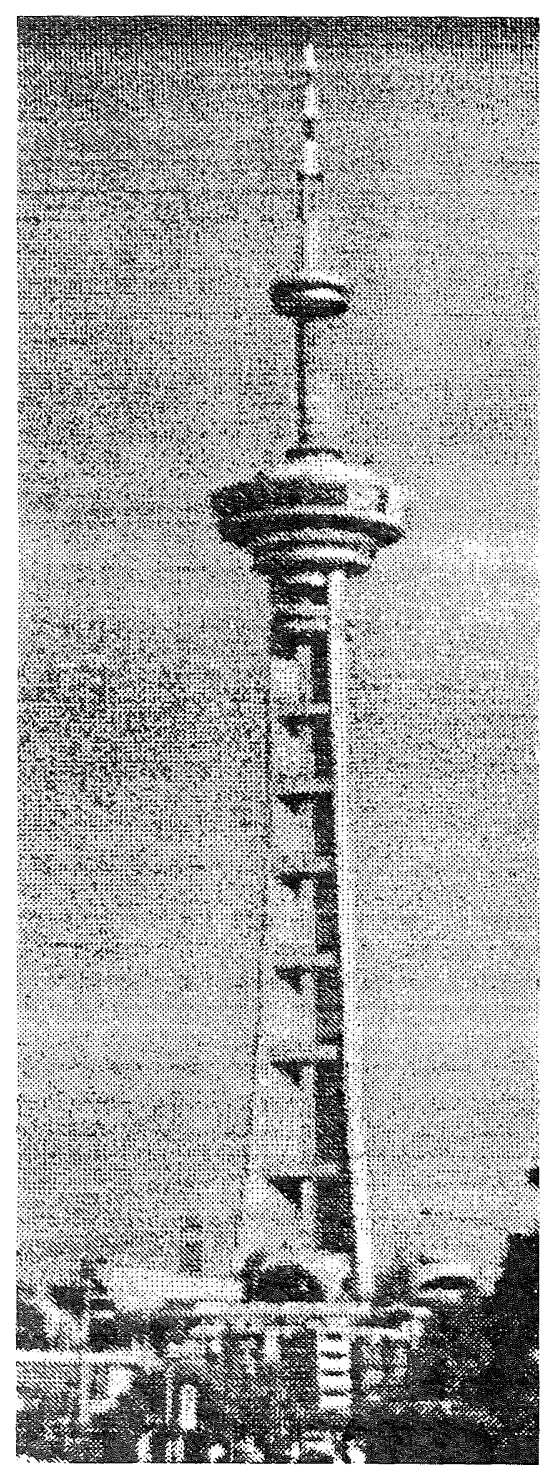

Figure 9: Nanjing Communication Tower
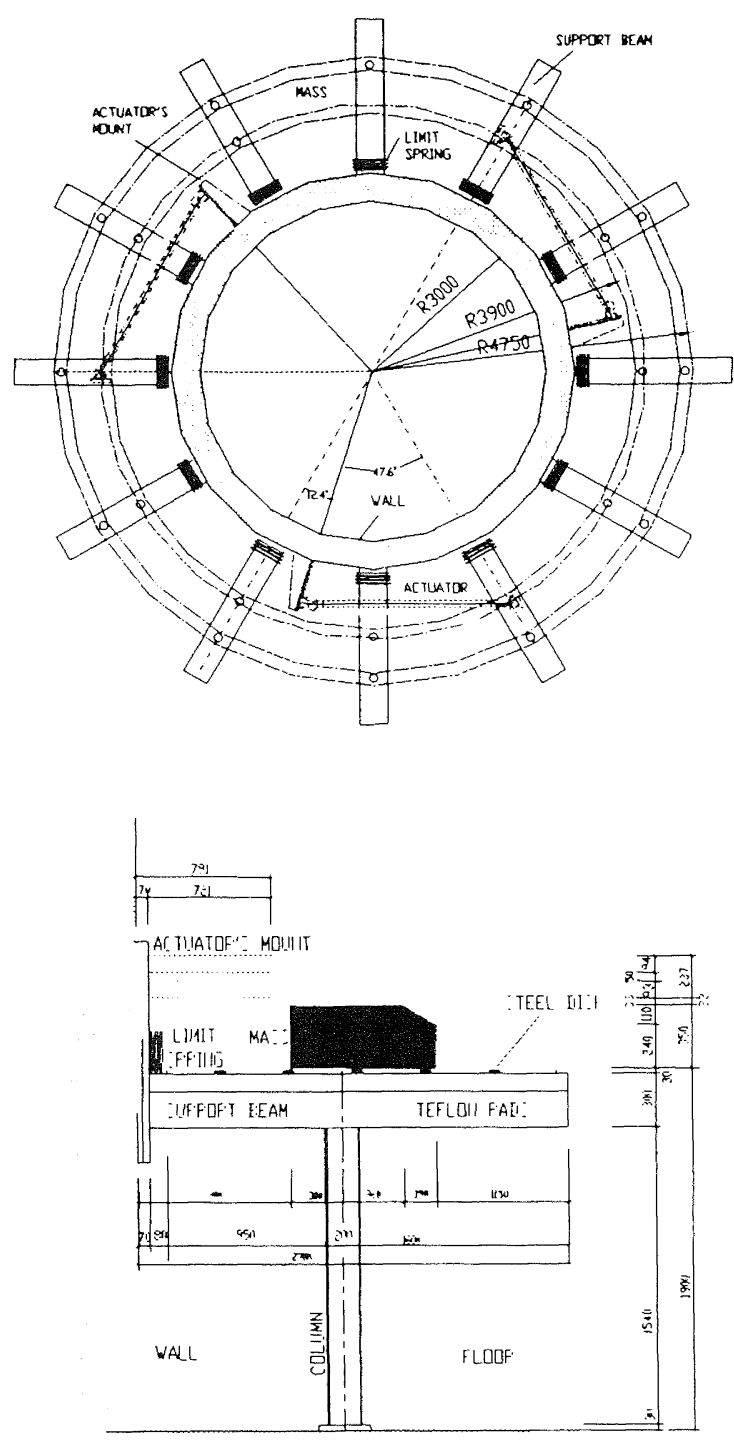

Figure 10: Design of AMD

\section{Semi-active Damper Systems}

Control strategies based on semi-active devices appear to combine the best features of both passive and active control systems. The close attention received in this area in recent years can be attributed to the fact that semiactive control devices offer the adaptability of active control devices without requiring the associated large power sources. In fact, many can operate on battery power, which is critical during seismic events when the main power source to the structure may fail. In addition, as stated earlier, semi-active control devices do not have the potential to destabilize (in the bounded input/bounded output sense) the structural system. Extensive studies have indicated that appropriately implemented semi-active systems perform significantly better than passive devices and have the potential to achieve the majority of the performance of fully active systems, thus allowing for the possibility of effective response reduction during a wide array of dynamic loading conditions. 
One means of achieving a semi-active damping device is to use a controllable, electromechanical, variableorifice valve to alter the resistance to flow of a conventional hydraulic fluid damper. A schematic of such a device is given in Fig. 11. Sack and Patten [1993] conducted experiments in which a hydraulic actuator with a controllable orifice was implemented in a single-lane model bridge to dissipate the energy induced by vehicle traffic, followed by a full-scale experiment conducted on a bridge on interstate highway I-35 to demonstrate this technology [Patten, 1998]. This experiment constitutes the first full-scale implementation of structural control in the US.

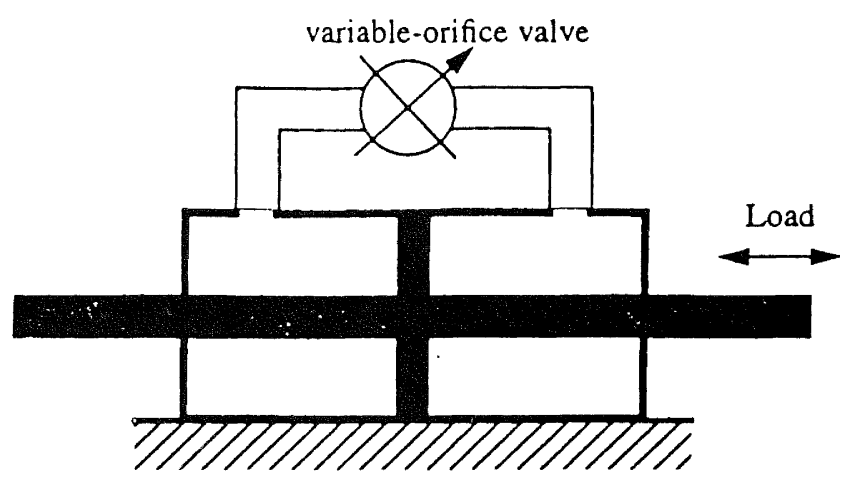

Figure 11: Schematic of Variable-Orifice Damper

Conceived as a variable-stiffness device, Kobori et al [1993] and Kamagata and Kobori [1994] implemented a full-scale variable-orifice damper in a semi-active variable-stiffness system (SAVS) to investigate semi-active control at the Kobori Research Complex. The overall system is shown in Fig. 12 where SAVS devices were installed on both sides of the structure in the longitudinal direction. The results of these analytical and experimental studies indicate that this device is effective in reducing structural responses.

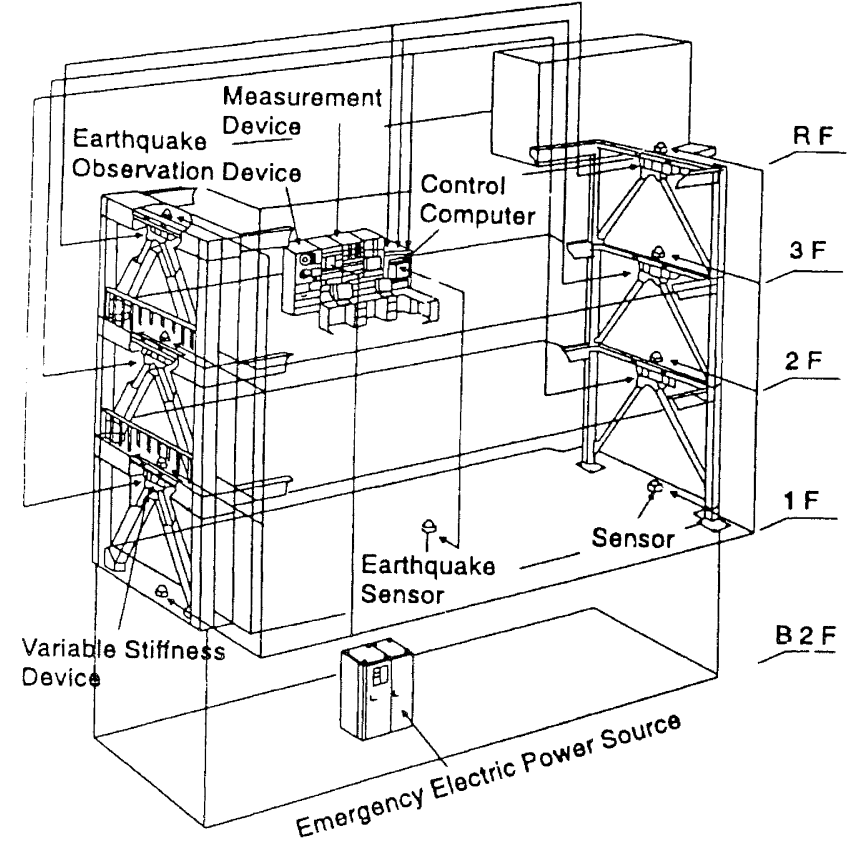

Figure 12: SAVS System Configuration

More recently, a semi-active damper system was installed in the Kajima Shizuoka Building in Shizuoka, Japan. As seen in Fig. 13, semi-active hydraulic dampers are installed inside the walls on both sides of the building to enable it to be used as a disaster relief base in post-earthquake situations [Kobori, 1998; Kurata et al, 1999]. Each damper contains a flow control valve, a check valve and an accumulator, and can develop a maximum damping force of $1000 \mathrm{kN}$. Figure 14 shows a sample of the response analysis results based on one of the selected control schemes and several earthquake input motions with the scaled maximum velocity of $50 \mathrm{~cm} / \mathrm{sec}$, together with a simulated Tokai wave. It is seen that both storey shear forces and storey drifts are greatly reduced with control activated. In the case of the shear forces, they are confined within their elastic-limit values (indicated by E-limit) while, without control, they would enter the plastic range. 

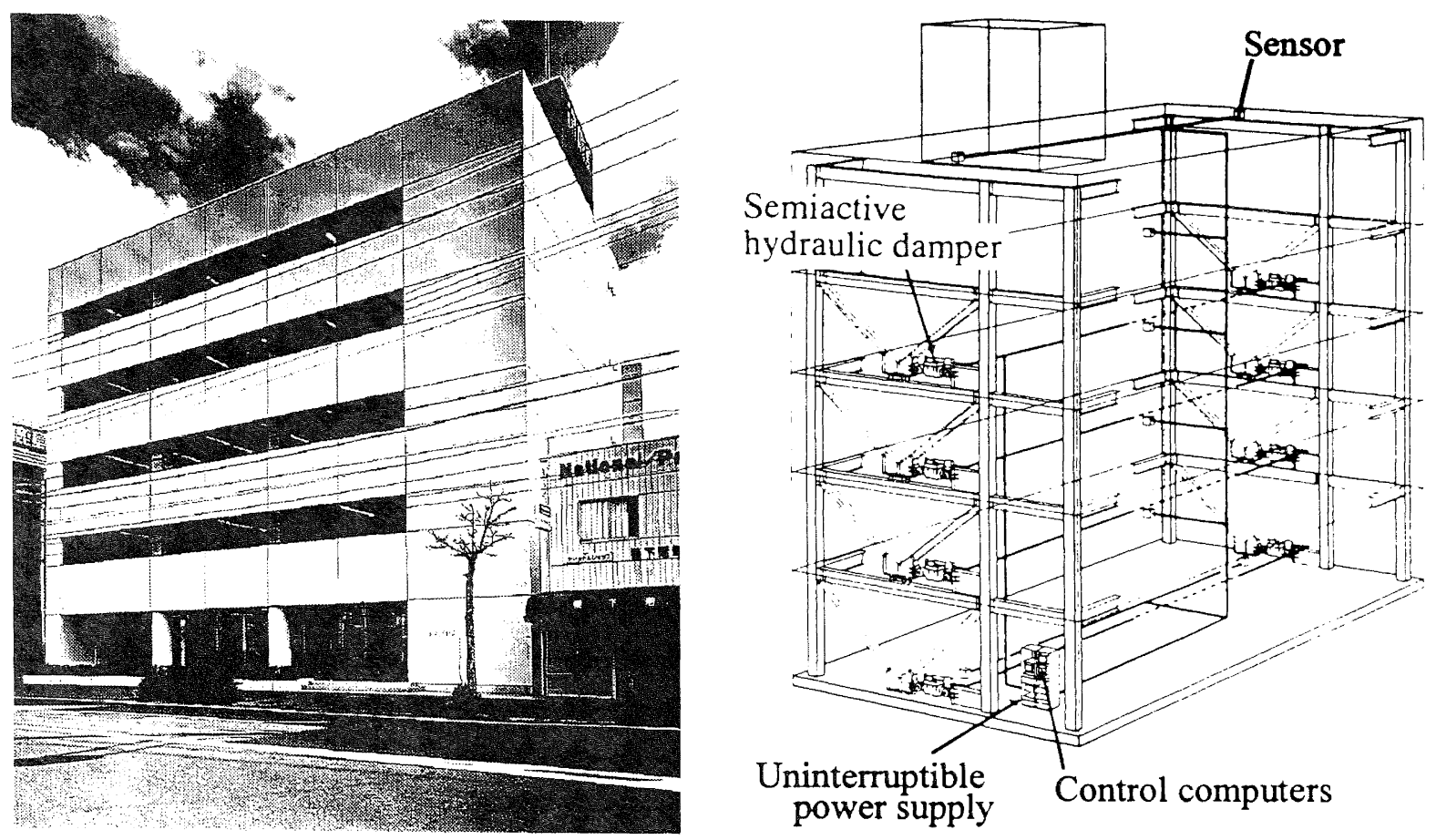

Figure 13: Kajima Shizuoka Building and Semi-active Hydraulic Damper

\section{Semi-active Controllable Fluid Dampers}

Another class of semi-active devices uses controllable fluids, schematically shown in Fig. 15 . In comparison with semi-active damper systems described above, an advantage of controllable fluid devices is that they contain no moving parts other than the piston, which makes them simple and potentially very reliable.

The essential characteristics of controllable fluids is their ability to reversibly change from a free-flowing, linear viscous fluid to a semi-solid with a controllable yield strength in milliseconds when exposed to an electric [for electrorheological (ER) fluids] or magnetic [for magnetorheological (MR) fluids] field.

In the case of magnetorheological fluids, they typically consist of micron-sized, magnetically polarizable particles dispersed in a carrier medium such as mineral or silicone oil. When a magnetic field is applied to the fluid, particle chains form, and the fluid becomes a semi-solid and exhibits viscoplastic behavior. Transition to rheological equilibrium can be achieved in a few milliseconds, allowing construction of devices with high bandwidth. Additionally, Carlson and Weiss [1994] indicated that high yield stress of a magnetorheological fluid can be achieved and that magnetorheological fluids can operate at temperatures from $-40^{\circ} \mathrm{C}$ to $150^{\circ} \mathrm{C}$ with only slight variations in the yield stress. Moreover, magnetorheological fluids are not sensitive to impurities such as are commonly encountered during manufacturing and usage, and little particle/carrier fluid separation takes place in magnetorheological fluids under common flow conditions. Further, a wider choice of additives (surfactants, dispersants, friction modifiers, antiwear agents, etc.) can generally be used with magnetorheological fluids to enhance stability, seal life, bearing life, and so on, since electrochemistry does not affect the magnetopolarization mechanism. The magnetorheological fluid can be readily controlled with a low voltage (e.g., 12-24 V), current-driven power supply outputting only 1-2 amps.

While no full-scale structural applications of magnetorheological devices have taken place to date, their future for civil engineering applications appears to be bright. Spencer et al [1996, 1997] and Dyke et al [1996a-c] have conducted a number of pilot studies to assess the usefulness of magnetorheological dampers for seismic response reduction. Dyke et al [1996a-c] have shown through simulations and laboratory experiments that the magnetorheological damper, used in conjunction with recently proposed acceleration feedback control strategies, significantly outperforms comparable passive configurations of the damper for seismic response reduction. In addition, Carlson and Spencer [1996] and Spencer et al [1997, 1998] report on the design of a full-scale, 20-ton magnetorheological damper (see Fig. 16) showing that this technology is scalable to devices appropriate for civil engineering applications. At design velocities, the dynamic range of forces produced by this device is over 10 (see Fig. 17), and the total power required by the device is only $20-50 \mathrm{~W}$. 

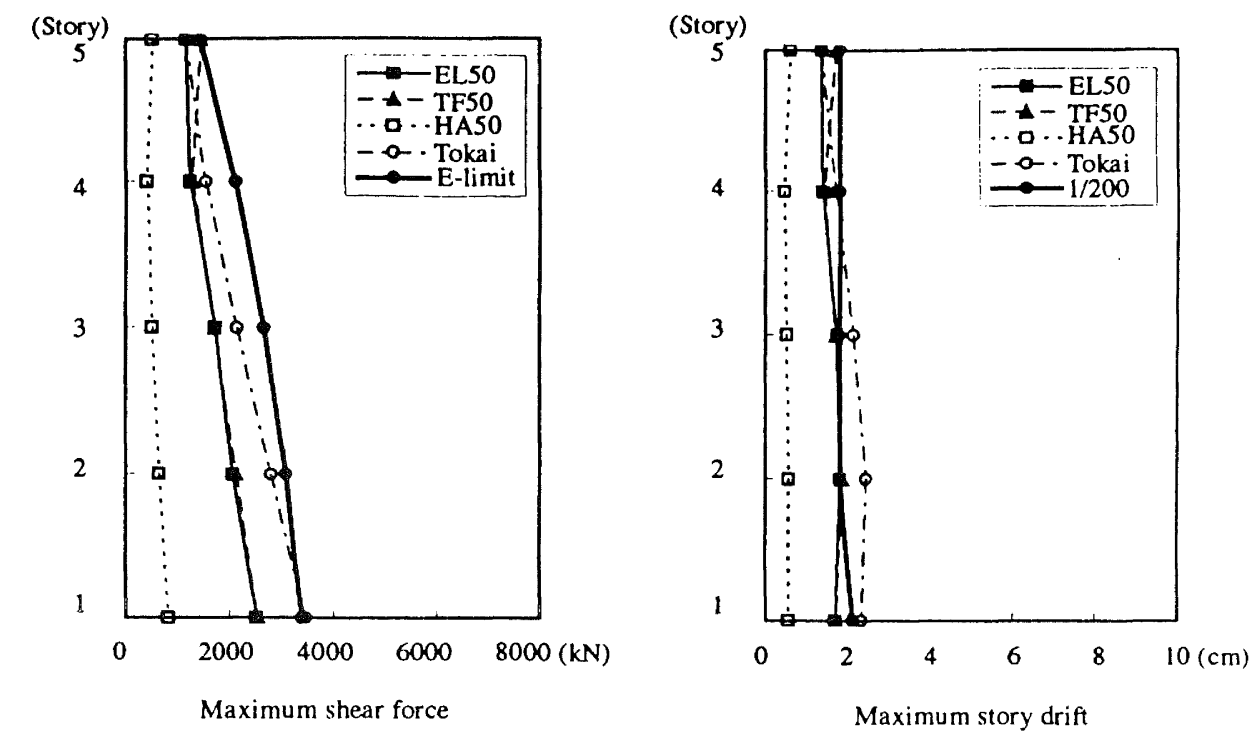

(a) With SAHD Control
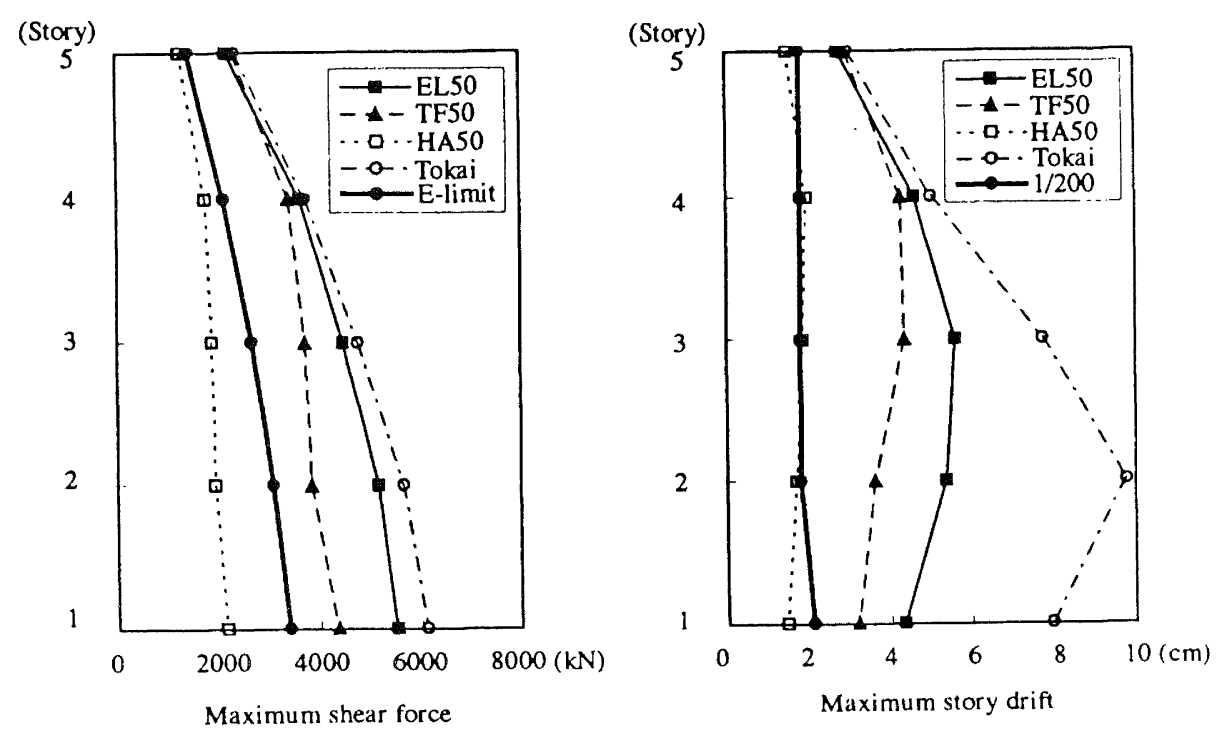

(b) Without Control

Figure 14: Maximum Responses

(El Centro, Taft and Hachinohe Waves with $50 \mathrm{~cm} / \mathrm{sec}$ and Assumed Tokai Waves)

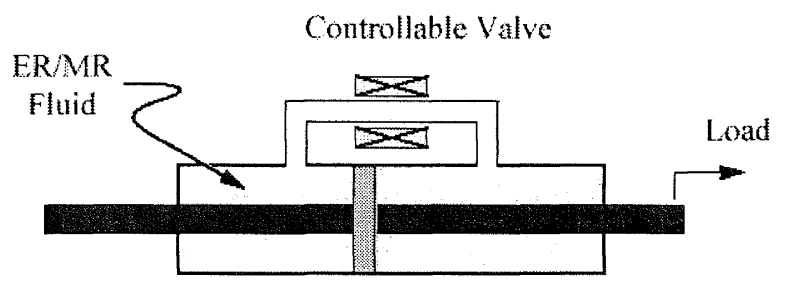

Figure 15: Schematic of Controllable Fluid Damper 


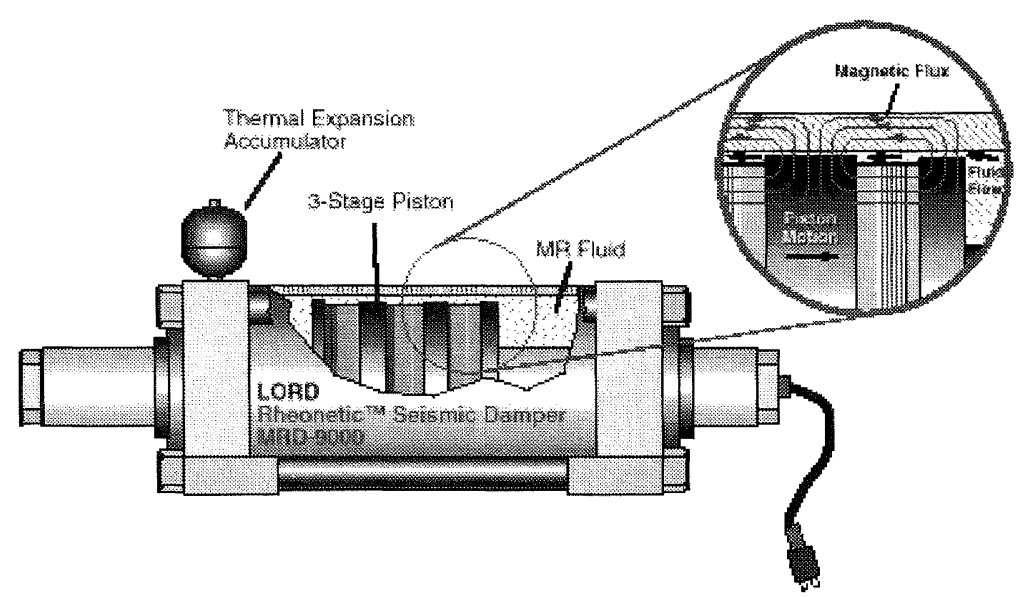

Figure 16: Full-scale 20-ton MR Fluid Damper

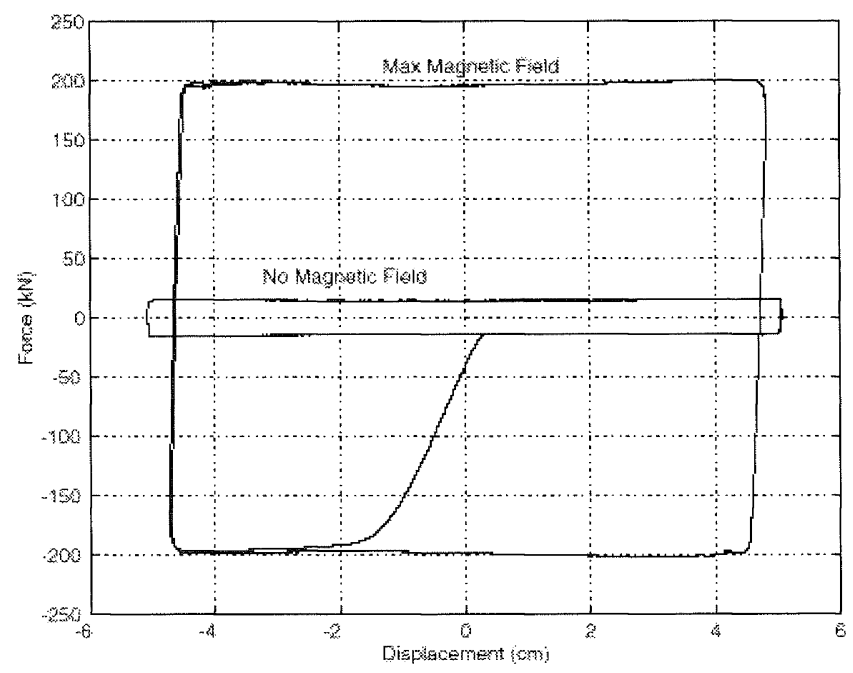

Figure 17: Force-displacement Loops at Maximum and Zero Magnetic Fields

\section{CONCLUDING REMARKS AND POSSIBLE FUTURE DIRECTIONS}

While great strides have been, and are being, made in research and development of active structural control systems for natural hazard mitigation, there remains a significant distance between the state-of-the-art of active control technology and some originally intended purposes for developing such a technology. Two of these areas are particularly noteworthy and they are highlighted below.

1. Mitigating Higher Level Hazards. In the context of earthquake engineering, one of the original goals for active control research was the desire that, through active control, conventional structures can be protected against infrequent, but highly damaging earthquakes. The active control devices currently deployed in structures and towers were designed primarily for performance enhancement against wind and moderate earthquakes and, in many cases, only for occupant comfort. However, active control systems remain to be one of only a few alternatives for structural protection against near-field and high-consequence earthquakes.

An upgrade of current active systems to this higher level of structural protection is necessary, since only then can the unique capability of active control systems be realized. In this regard, collaboration on a global scale is essential and must be nurtured and reinforced.

2. Economy and Flexibility in Construction. Another area in which great benefit can be potentially realized by the deployment of active control systems is added economy and flexibility to structural design and 
construction. In Soong and Manolis [1987], the concept of active structures, is advanced. An active structure is defined here as one consisting of two types of load resisting members: the traditional static (or passive) members that are designed to support basic design loads, and dynamic (or active) members whose function is to augment the structure's capability in resisting extraordinary dynamic loads. Their integration is done in an optimal fashion and produces a structure that is adaptive to changing environmental loads and usage.

Note that an active structure is conceptually and physically different from a structure that is actively controlled, as in the cases described above. In the case of a structure with active control, a conventionally designed structure is supplemented by an active control device that is activated whenever necessary in order to enhance structural performance under extraordinary loads. Thus, the structure and the active control system are individually designed and optimized. An active structure, on the other hand, is one whose active and passive components are integrated and simultaneously optimized to produce a new breed of structural systems. This important difference makes the concept of active structures exciting and potentially revolutionary. Among many possible consequences, one can envision greater flexibilities which may lead to longer, taller, slender or more open structures and structural forms.

To be sure, some progress has been made in this direction. For example, according to Seto [1998], the Kurusima Bridge in Shikoku area, Japan, was designed with the application of active vibration control as integrated structural components. Several modes of the bridge tower, which were anticipated to be excited by wind vortex, were carefully protected by appropriate controllers during the construction phase. It therefore made it possible for the tower of this bridge to be built much lighter and more slender than one following traditional design.

\section{ACKNOWLEDGEMENTS}

The first author wishes to acknowledge the generous support for this work received from the Multidisciplinary Center for Earthquake Engineering Research, Buffalo, NY. The second author gratefully acknowledges the partial support of this work by the National Science Foundation under grant CMS-9900234 (Dr. S.C. Liu, Program Director) and Lord Corporation. The authors are grateful to Professor T. Kobori of the Kobori Research Complex, Inc., Professor T. Fujita of the University of Tokyo, Professor A. Nishitani of Waseda University and Professor K.C. Chang of the National Taiwan University for their contributions, making this paper more complete on a global scale.

\section{REFERENCES}

Baker, G.A., Johnson, E.A., Spencer Jr., B.F. and Fujino, Y. (1999), "Modeling and semiactive damping of stay cables", Proc. $13^{\text {th }}$ ASCE Engrg. Mech. Conf., Baltimore, Maryland, 6 pages (CD-ROM).

Carİson, J.D. and Spencer Jr., B.F. (1996), "Magneto-rheological fluid dampers for semi-active seismic control",

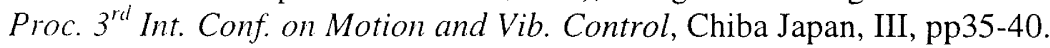

Carlson, J.D. and Weiss, K.D. (1994), "A growing attraction to magnetic fluids", Machine Design, pp61-64.

Dyke, S.J., Spencer Jr., B.F., Quast, P. and Sain, M.K. (1995), "The role of control-structure interaction in protective system design", J. Engrg. Mech., ASCE, 121(2), pp322-338.

Dyke, S.J., Spencer Jr., B.F., Sain, M.K. and Carlson, J.D. (1996a), "Experimental verification of semi-active structural control strategies using acceleration feedback", Proc. $3^{\text {rd }}$ Int. Conf. on Motion and Vib. Control, Chiba, Japan, III, pp291-296.

Dyke, S.J., Spencer Jr., B.F., Sain, M.K. and Carlson, J.D. (1996b), "Modeling and control of magnetorheological dampers for seismic response reduction", Smart Mat. and Struct., 5, pp565-575.

Dyke, S.J., Spencer Jr., B.F., Sain, M.K. and Carlson, J.D. (1996c), "Seismic response reduction using magnetorheological dampers", Proc. IFAC World Congress, San Francisco, CA.

Dyke, S.J., Spencer Jr., B.F., Sain, M.K. and Carlson, J.D. (1998), "An experimental study of MR dampers for seismic protection", Smart Mat. and Struct., 7, pp693-703.

Fujino, Y. (1994), "Recent research and developments on control of bridges under wind and traffic excitations in Japan", Proc. Int. Workshop on Struct. Control, pp144-150.

Higashino, M. and Aizawa, S. (1993), "Application of active mass damper system in actual buildings", G.W. Housner and S.F. Masri (eds), Proc. Int. Workshop on Structural Control, pp194-205, Los Angeles, CA. 
Housner, G.W., Bergman, L.A., Caughey, T.K., Chassiakos, A.G., Claus, R.O., Masri, S.F., Skelton, R.E., Soong, T.T., Spencer Jr., B.F. and Yao, T.P. (1997), "Structural control: Past, present, and future", J. Engrg. Mech., ASCE, 123(9), pp897-971.

Housner, G., Soong, T.T. and Masri, S.F. (1994a), "Second generation on active structural control in civil engineering”, Proc. 1st World Conf. on Struct. Control, ppFA2:3-18, Pasadena, CA.

Housner, G.W., Masri, S.F. and Chassiakos, A.G. (eds) (1994b), Proc. 1st World Conf. on Struct. Control, Pasadena, CA.

Kamagata, S. and Kobori, T. (1994), "Autonomous adaptive control of active variable stiffness systems for seismic ground motion", Proc. I $^{\text {st }}$ World Conf. on Struct. Control, ppTA4:33-42, Pasadena, CA.

Kobori, T. (1998), "Mission and perspective towards future structural control research", Proc. of $2^{\text {nd }}$ World Conf. in Struct. Control, 1, pp25-34, Kyoto, Japan.

Kobori, T., Inou, Y., Seto, K., Iemura, H. and Nishitani, A. (eds.) (1998), Proc. $2^{\text {nd }}$ World Conf. on Struct. Control, Kyoto, Japan.

Kobori, T., Takahashi, M., Nasu, T., Niwa, N. and Ogasawara, K. (1993), "Seismic response controlled structure with active variable stiffness system”, Earthquake Engrg. and Struct. Dyn., 22, pp925-941.

Kobori, T. (1994), "Future direction on research and development of seismic-response-controlled structure", Proc. 1st World Conf. on Struct. Control, Panel, pp19-31, Pasadena, CA.

Kurata, N., Kobori, T., Takahashi, M., Niwa, N. and Midorikawa, H. (1999), "Actual seismic response controlled building with semi-active damper system," Earthquake Engrg. and Struct. Dyn., in press.

Patten, W.N. (1998), "The I-35 Walnut Creek Bridge: An intelligent highway bridge via semi-active structural control", Proc. $2^{\text {nd }}$ World Conf. on Struct. Control, 1, pp427-436, Kyoto, Japan.

Reinhorn, A.M., Soong, T.T., Helgeson, R.J., Riley, M.A. and Cao, H. (1998), "Analysis, design and implementation of an active mass damper for a communication tower", Proc. $2^{\text {nd }}$ World Conf. on Struct. Control, 3, pp 1727-1736, Kyoto, Japan.

Sack, R.L. and Patten, W (1993), "Semiactive hydraulic structural control", Proc. Int. Workshop on Struct. Control, USC Publication Number CE-9311, pp417-431, Honolulu, Hawaii.

Seto, K. (1998), "Modeling and active vibration control of flexible structures", Proc. of $2^{\text {nd }}$ World Conf. on Struct. Control, 1, pp15-24, Kyoto, Japan.

Soong, T.T. (1990), Active Structural Control: Theory and Practice, Longman, England and Wiley, New York, NY.

Soong, T.T. and Manolis, G.D. (1987), “Active structures”, J. Struct. Engrg., ASCE, 113(11), pp2290-2301.

Soong, T.T., Reinhorn, A.M., Aizawa, S. and Higashino, M. (1994), "Recent structural applications of active control technology", J. Struct. Control, 1(2), pp5-21.

Spencer Jr., B.F., Carlson, J.D., Sain, M.K. and Yang, G. (1997) "On the current status of magnetorheological dampers: Seismic protection of full-scale structures”, Proc. American Control Conf., pp458-462, Albuquerque, NM.

Spencer Jr., B.F., Dyke, S.J., Sain, M.K. and Carlson, J.D. (1996), "Idealized model of a magnetorheological damper", Proc. 12 ${ }^{\text {th }}$ Conf. on Analysis and Computation, ASCE, pp361-370, Chicago, IL.

Spencer Jr., B.F., Dyke, S.J., Sain, M.K. and Carlson, J.D. (1997), "Phenomenological model of a magnetorheological damper", J. Engrg. Mech., ASCE, 123(3), pp230-238.

Spencer Jr., B.F. and Sain, M.K. (1997), "Controlling buildings: A new frontier in feedback", IEEE Control Systems Magazine: Special Issue on Emerging Technologies, 17(6), pp19-35.

Spencer Jr., B.F., Yang, G., Carlson, J.D. and Sain, M.K. (1998), "Smart dampers for seismic protection of structures: A full-scale study", Proc. of $2^{\text {nd }}$ World Conf. on Struct. Control, 1, pp417-426, Kyoto, Japan.

Spencer Jr., B.F., Johnson, E.A. and Ramallo, J.C. (1999), "Smart isolation for seismic control", Proc. Pioneering Int. Symp. on Motion and Vib. Control in Mechatronics, Tokyo, Japan, pp 169-174.

Suhardjo, J., Spencer Jr., B.F. and Sain, M.K. (1990), "Feedback-feedforward control of structures under seismic excitation", Struct. Safety, 8, pp69-89.

Yamazaki, S., Nagata, N., and Abiru, H. (1992), "Tuned active dampers installed in the Minato Mirai (MM) 21 Landmark Tower in Yokohama”, J. Wind Engrg. and Indust. Aerodyn., 43, pp 1937-1948 